\title{
Surgical Outcomes of Synovial Osteochondromatosis: An Evaluation of 15 Cases
}

\section{Sinovyal Osteokondromatoziste Cerrahi Sonuçlarımız: 15 Olgunun Değerlendirilmesi}

\author{
İsmail Burak Atalay, Aliekber Yapar, Recep Öztürk, Coşkun Ulucaköy, Ethem Toptaş, Yaman Karakoç \\ Ankara Onkoloji Eğitim ve Araştırma Hastanesi Ortopedi ve Travmatoloji Bölümü, Ankara
}

\section{ÖZET}

GİRIŞ ve AMAÇ: Bu çalışmada sinovyal osteokondromatozis nedeniyle kliniğimizde takip ve tedavisi yapılan 15 hasta değerlendirilmiştir.

YÖNTEM ve GEREÇLER: Sinovyal osteokondromatozisli 15 hastanın (9 erkek, 6 kadın; ort. yaş 43; dağılım 16-72 yaş), tutulum yerleri sıklık sırasına göre diz $(n=6)$, omuz $(n=3)$, kalça $(n=2)$, dirsek $(n=2)$ ve ayak bileği $(\mathrm{n}=2)$ idi. On üç hastaya açık cerrahi ile total sinovyektomi ve serbest fragman eksizyonu uygulandı. Tanılar bütün hastalarda histopatolojik olarak doğrulandı. İki hasta operasyonu kabul etmedi ve konservatif tedaviye alındı. Ortalama takip süresi 71 aydı. (dağılım 12-204 ay).

BULGULAR: On üç hastanın birinde on altı ay sonra nüks görüldü. Hastaya yeniden total sinovyektomi yapıldı ve sonraki takiplerinde ikinci bir nükse rastlanmadı. Hiçbir hastada malign transformasyon gözlenmedi. Cerrahi sonrası hastaların ağrı şikayetlerinde belirgin düzelme gözlendi. Konservatif tedavi ile takip edilen hastalarda ağrı ve hareket kısıtlılığının devam ettiği görüldü.

TARTIŞMA ve SONUÇ: Çalışmamızın sonucunda diz ekleminin en sık tutulan eklem olduğu ve görülme sıklığı açısından cinsiyet farkının olmadı̆̆ı görüldü. Hastaların cerrahi sonrası nüks açısından takip edilmesi gerekmektedir. Cerrahi tedavi uygulanamayan hastalarda fizik tedavinin sinoviyal kondromatoziste etkinliği ile ilgili daha fazla çalışmaya ihtiyaç vardır. Olgular sıklıkla spesifik olmayan klinik semptomlarla başvurduğundan ağrı ve şişlik ile başvuran hastalarda sinovyal osteokondromatozisin mutlaka akılda tutulması gerekmektedir.

Anahtar Kelimeler: Osteokondromatozis, sinovyal, cerrahi, fizik tedavi ve rehabilitasyon

\section{ABSTRACT}

INTRODUCTION: In this study, we evaluated 13 patients who were treated and followed-up for synovial chondromatosis in our clinic.

METHODS: Fifteen patients (9 males, 6 females,; mean age 43 years; range 16 to 72 years) had synovial chondromatosis localized in the knee $(n=6)$, shoulder $(n=3)$, hip $(n=2)$, elbow $(n=2)$, and ankle $(n=2)$. Joint loose bodies were removed together with total synovectomy by open surgery in thirteen patients. Histopathologic confirmation was obtained in all the patients. Two patients refused surgical treatment and were treated conservatively. The mean follow-up period was 71 months (range 12 to 204 month).

RESULTS: One patient developed recurrence sixteen months after surgery, for which repeat total synovectomy was performed in the shoulder and no other recurrences were observed. No malignant transformation was observed in any patient. Symptomatic improvement was obtained in all the patients with treated surgically. Pain and limitation of motion were observed in the patients who were followed up conservatively.

DISCUSSION AND CONCLUSION: As a result of our study, it was found that the knee joint was the most commonly involved joint and there was no gender difference in terms of incidence. All patients must be followed-up with regard to recurrence. Further studies are needed on the efficacy of physical therapy in synovial chondromatosis in patients without surgical treatment. Patients often present with non-specific clinical symptoms. Therefore, synovial osteochondromatosis should be kept in mind in patients presenting with pain and swelling.

Keywords: Osteochondromatosis, synovial, surgery, physical therapy and rehabilitation

\section{GíRIŞ}

Sinovyal osteokondromatozis, sinovyal membranın kartilajinöz proliferasyonu sonucu sinovyumda kondral veya osteokondral odakların oluşması ile gelişen nadir bir eklem içi yerleşimli benign tümördür (1). Etyolojisinde travma ya da enfeksiyona bağlı 
sinovyal irritasyon sorumlu tutulmaktadir. Kartilajinöz lezyonlar eklem içinde serbest cisimler haline dönüşüp sekonder dejeneratif değişikliklere neden olabilir. Çoğunlukla 30-50 yaşlar arasında erkeklerde görülür. En sik tutulum diz ekleminde sonrasinda daha az sıklıkla dirsek, omuz, kalça ve ayak bileği eklemlerinde görülmektedir (2,3). Klinik olarak hastalarda eklem yüzeyindeki hasarla ilişkili olarak progresif artan eklem ağrısı bulunmaktadır. Bazı olgularda ağrıya eklemde effüzyon, kilitlenme ve instabilite de eşlik edebilmektedir (4).

Çalıșmamızda

sinovial osteokondromatozis nedeniyle kliniğimizde takip ve tedavisi yapilan 15 hasta değerlendirilmiştir.

\section{GEREÇ ve YÖNTEM}

Çalışmaya, 2002-2018 yılları arasında primer sinovyal osteokondromatozis tanisi alan 15 hasta (9 erkek, 6 kadın; ortalama yaş 43; dağılım 16-72 yaş) alındı. Tutulum yerleri altı hastada diz (Şekil 1), üç hastada omuz (Şekil 2), iki hastada dirsek (Şekil 3), iki hastada kalça ve iki hastada ayak bileği eklemi idi. Hastaların tamamına radyolojik tetkik (düz radyografi, manyetik rezonans görüntüleme) uygulaması yapıldı. On üç hastaya cerrahi tedavi uyguland1. Tanılar eksizyonel biyopsi ve total sinovyektomi sonras1 histopatolojik olarak doğrulandi. Ayak bileği yerleşimli bir olgu ve kalça yerleşimli bir olgu cerrahiyi kabul etmedi. Hastaların ortalama takip süresi 71 aydı. (dağılım 12-204 ay)

\section{BULGULAR}

Total sinovyektomi ve serbest cisim eksiyonu yapılan 13 hastanın birinde on altı ay sonra nüks görüldü. Hastanın omuz eklemine yönelik total sinovyektomi yenilendi ve takiplerinde ikinci bir nükse rastlanmadı. Hiçbir hastada malign transformasyon gözlenmedi. Cerrahi tedavi yapılan 13 hastanın tamamında tanılar histopatolojik inceleme ile doğrulandi. Cerrahi sonrası hastaların ağrı şikayetlerinde belirgin düzelme gözlendi. Cerrahi tedavi uygulanan hastalarda takiplerde radyolojik olarak eklem dejenerasyon bulguları gözlenmedi. Konservatif tedavi ile takip edilen hastalarda ağrı ve hareket kısitlılığının devam ettiği görüldü.

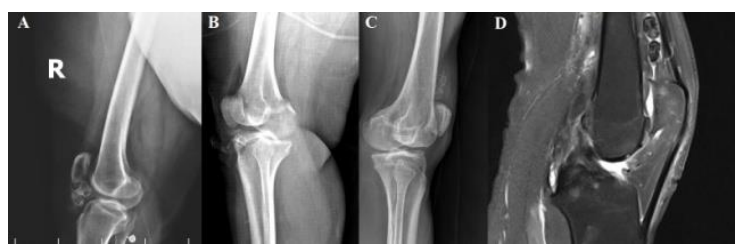

Şekil 1: Sağ diz synovial osteokondromatozisli olgunun preoperatif (A) ve postoperatif (B) radyolojik görüntüleri. Sol diz suprapatellar sinovial osteokondromatozis; direk grafi (C) ve MRG (D)

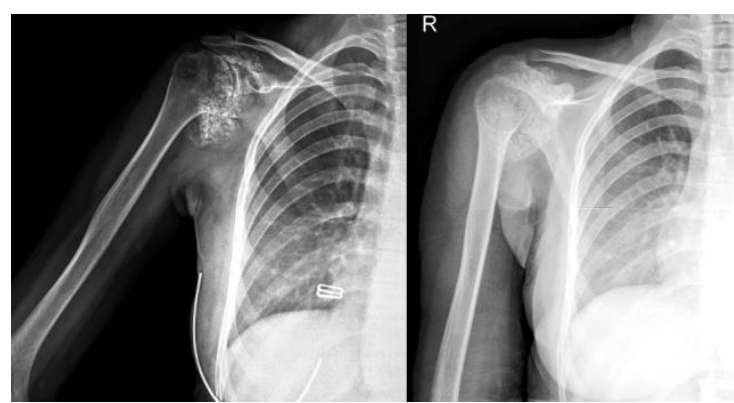

Şekil 2: Sağ omuz sinovyal osteokondromatozis, direk grafi görüntüsü

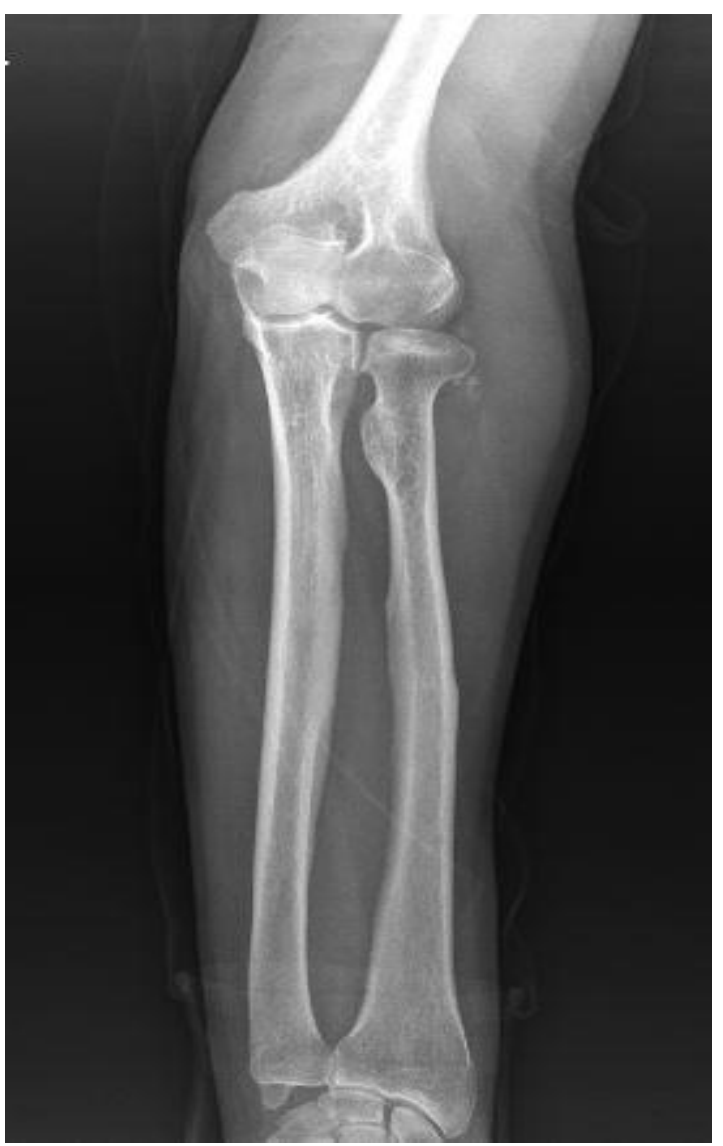

Şekil 3: Dirsek osteokondramotizisi, direk grafi görüntüsü 


\section{TARTIŞMA}

Sinovyal osteokondromatozis, sinovyal membranın kartilajinöz metaplazisi sonucu gelişen, nadir görülen, sinsi başlangıçlı bir hastalıktır. Genellikle tek ve büyük eklem tutulumu görülür. Primer sinovyal osteokondromatoziste en sik diz eklemi tutulmakta olup, oluşum mekanizmasında travma ve enfeksiyonlar suçlansa da etiyolojisi henüz tam olarak bilinmemektedir $(3,5,6)$. Sinovyal kondromatozis dejeneratif eklem hastalığına, osteokondritis dissekansa, tüberküloz artrit ve osteokondral kırıklar gibi diğer eklem hastalıklarına bağlı olarak da gelişebilir. $\mathrm{Bu}$ durumda sekonder sinovyal osteokondromatozis olarak adlandırılır $(3,5)$.

Milgram (7) tarafindan hastalığın 3 evresi tanımlanmıştır. Erken dönem olarak tanımlanan Evre I hastalik, eklemde serbest cisimlerin olmadığ 1 aktif intrasinovyal dönemdir. Geçiş dönemi olarak tanımlanan Evre 2 hastalıkta, eklem içinde aktif intrasinovyal hastalık ve serbest cisim mevcuttur. Geç dönem olan Evre 3'te ise eklem içinde intrasinovyal tutulum olmaksızın çok sayıda serbest cisim vardır. Hastalığın tanısı ağrı ve şişlik gibi spesifik olmayan klinik semptomlardan ötürü sıklıkla gecikir. Tanı konduğunda 2 hastamızda Evre 2 diğer hastalarda Evre 3 hastalık mevcuttu.

Literatürde sinovyal osteokondromatozisin klinik semptomları en sık ağrı (\%85-100) sonrasında şişlik (\%42-58) ve eklem hareket açıklığında kısıtlanma (\%3855) olarak bildirilmiştir (8). Fizik muayenede eklemde diffüz şişlik (\%42-58), hassasiyet (\%20-41), krepitasyon (\%20-33), kilitlenme (\%5-12) ve palpabl kitle (\%3-20) saptanabilmektedir $(8,9)$. Olgularımızda en s1k başvuru şikayeti ağrı, en sık fizik muayene bulgusu ise şişlik ve krepitasyon olarak saptanmıştır.

Sinovyal osteokondromatozisin tanısında klinik muayene, düz radyografiler, ultrasonografi, BT ve MRG kullanılabilmektedir. Radyolojik olarak nodüllerdeki kalsifikasyon ya da ossifikasyon varlığ 1 tanıda önemli olmakla birlikte \%30 oranında nodülün kalsifikasyon içermemesinden dolayı direk grafide görülemeyeceği unutulmamalıdır. Manyetik rezonans görüntülemede (MRG) kalsifiye cisimler ve henüz mineralize olmamış nodüller de kolaylikla tespit edilebilmektedir $(9,10)$. Aynı zamanda ayırıcı tanida yer alan hemanjiom, pigmente villonodüler sinovit, kondrosarkom ve sinovyal sarkom gibi tümörlerden ayırımı da manyetik rezonans görüntüleme ile kolaylıkla yapılabilmektedir. $\mathrm{Bu}$ nedenle, hastalığın erken tanısında $\mathrm{MRG}$ en yararlı yöntemdir $(9,10,11)$.

Anract ve ark. (12) uzun süreli takiplerde malign dönüşümün oldukça nadir olduğunu söylemişler ve hastada kemik tutulumu ile klinik tabloda hızlı ilerleme varlığında malign transformasyondan şüphelenilmesi gerektiğini bildirmişlerdir. Çalışmamızda hiçbir hastada takiplerde malign transformasyona rastlanılmadı.

Sinovyal osteokondromatozisin tedavisi total sinovyektomi ile birlikte eklem içi serbest cisimlerin eksiyonudur $(3,5,13)$. Cerrahi açık ya da artroskopik olarak yap1labilmektedir. Son y1llarda bazı merkezlerde uygun vakalarda, hastalığın tutulum lokalizasyonu göz önüne alınarak daha az morbidititasyona yol açması nedeniyle artroskopik tedavi tercih edilmektedir $(3,14)$.

Literatürde sinovyal

osteokondromatoziste cerrahi dışı konservatif tedavi uygulanan ve tek başına fizik tedavi ve rehabilitasyonun etkinliğini gösteren yayınlar da mevcuttur. McFarland ve ark. (15) omuz osteoartritine sekonder sinovyal osteokondromatozisi olan iki hastalarına aktivite kisitlamas1, non-steroid antiinflamatuvar ilaç ve buz tedavisi uygulamışlar, sonrasında iki olgunun da cerrahi tedaviye ihtiyacı kalmadığını bildirmişlerdir. Ülkemizden bildirilen bir olgu sunumunda ise Taştaban ve ark. (8) diz yerleşimli sinovyal osteokondromatozisli hastalarına soğuk paket, kesikli ultrason, magnetoterapi ile dizlere $111 \mathrm{ml}$ germe, eklem hareket açıklığı, düz bacak kaldırma ve kuadriseps kas güçlendirme egzersizlerinden oluşan fizik tedavi ve rehabilitasyon programı uygulamışlar, tedavi sonrasında hastanın klinik ve fonksiyonel değerlendirme skorlarında anlamlı iyileşme olduğunu rapor etmişlerdir. Çalışmalarında sinovyal osteokondromatozisli hastalara cerrahi öncesi fizik tedavi ve rehabilitasyon programı uygulaması için şans verilmesi gerektiğini belirtmişlerdir. Biz de cerrahi tedaviyi kabul etmeyen iki hastamızı fizik tedavi ve rehabilitasyon programı uygulanması amaciyla ilgili kliniğe 
yönlendirdik. Ancak takiplerde iki hastanın da şikayetlerinde belirgin bir düzelme saptayamadik.

Literatür incelendiğinde nadiren nüks olguları da bildirilmiştir (16). Cerrahi tedavi ettiğimiz hastalarımızın yalnızca birinde sinovyektomi ve serbest cisim eksizyonu sonras1 on altınc1 ayda nüks görüldü. Hastamızda ikinci kez yapilan total sinovyektomi sonrası takiplerinde nüks gözlenmedi.

Sonuç olarak, literatür bilgileriyle uyumlu olarak bizim çalışmamızda da diz ekleminin en sik tutulan eklem olduğu ve görülme sıklığı açısından cinsiyet farkının olmadığ1 görüldü. Total sinovyektomi uygulamas1 sonras1 bir hastamızda nüks görülmesi nedeniyle, sinovyal osteokondromatozisli hastaların cerrahi sonrası nüks açısından takip edilmesi gerekmektedir. Cerrahi tedavi uygulanamayan hastalarda konservatif tedavi olarak fizik tedavi ve rehabilitasyon programı uygulanabilir. Ancak fizik tedavinin sinoviyal kondromatoziste etkinliği ile ilgili daha fazla çalışmaya ihtiyaç olduğunu düşünmekteyiz. Olgular sıklıkla ağrı ve şişlik gibi spesifik olmayan klinik semptomlarla başvurduğundan bu tür durumlarda sinovial osteokondromatozisin mutlaka akılda tutulması gerekmektedir

\section{REFERENCES}

1. Jonathan K, Schumacher HR. Miscellaneous arthropathies includ-ing synovial tumors and foreign body synovitis and nephrogenic systemic fibrosis. In Hochberg MC, Silman AJ, SmolenJS, Weinblatt ME, Weisman MH, editors. Rheumatology. 5th ed. Mosby Elsevier; 2011.p.1676-88.

2. Ackerman D, Lett P, Galat DD Jr, Parvizi J, Stuart MJ. Results of total hip and total knee arthroplasties in patients with synovial chondro-matosis. J Arthroplasty 2008;23:395-400.
3. Kerimoğlu S, Aynaci O, Saracoglu M, Synovial Chondromatosis: An Evaluation Of 13 Cases. Eklem Hastalik Cerrahisi. 2007; vol.18, pp.121-5.

4. Khan Z, Yousri T, Chakrabarti D, Awasthi R, Ashok N. Primary sy-novial osteochondromatosis of the first metatarsophalangeal joint, literature review of a rare presentation and a case report. Foot Ankle Surg 2010;16:1-3.

5. Chillemi C, Marinelli M, de Cupis V. Primary synovial chondromatosis of the shoulder: clinical, arthroscop-ic and histopathological aspects. Knee Surg SportsTraumatol Arthrosc 2005;13:483-8

6. Güngör BŞ, Ekşioğlu MF, Atalay İB. Eklem içi yerleşim gösteren tümör ve tümör benzeri oluşumların cerrahi tedavisinde güncel yaklaşımlar. Atik OŞ, editör. Eklem Hastalıkları Tedavisinde Güncel Yaklaşımlar. 1. Baskı. Ankara: Türkiye Klinikleri; 2019. p.80-5.

7. Milgram JW. Synovial osteochondromatosis: a histopathological study of thirty cases. J Bone Joint Surg [Am] 1977;59:792-801.

8. Tastaban, Engin, et al. "Knee joint synovial osteochondromatosis: a case/Diz eklemi sinovyal osteokondromatozisi: bir olgu. Turkish Journal of Physical Medicine and Rehabilitation vol. 2014; 60, no. 1.

9. Murphey MD, Vidal JA, Fanburg-Smith JC, Gajewski DA. Imaging of synovial chondromatosis with radiologic-pathologic correlation. Radiographics 2007;27:1465-88

10. Goel A, Cullen C, Paul AS, Freemont AJ. Multiple giant synovial chondromatosis of the knee. Knee 2001; 8:2435.

11. Joseph S. Musculoskeletal Imaging: Case Review Series. 2nd ed. Mosby Elsevier; 2008.p.81-2.

12. Anract $P$, Katabi $M$, Forest $M$, Benoit $J$, Witvoet $J$, Tomeno B. Synovial chondromatosis and chondrosarcoma. A study of the relationship between these two diseases. Rev Chir Orthop Reparatrice Appar Mot 1996; 82:216-24.

13. Jeon IH, Ihn JC, Kyung HS. Recurrence of syno-vial chondromatosis of the glenohumeral joint after arthroscopic treatment. Arthroscopy 2004;20:524-7.

14. Bruggeman NB, Sperling JW, Shives TC. Arthroscopic technique for treatment of synovial chondromatosis of the glenohumeral joint. Arthroscopy 2005;21:633.

15. McFarland EG, Neira CA. Synovial chondromatosis of the shoulder as-sociated with osteoarthritis: conservative treatment in two cases and review of the literature. Am J Orthop (Belle Mead NJ) 2000;29:785-7.

16. Loonen MP, Schuurman AH. Recurrent synovial chondromatosis of the wrist: case report and literature review. Acta Orthop Belg 2005;71:230-5 